\title{
Inducción in vitro de callogénesis y organogénesis indirecta a partir de explantes de cotiledón, hipocótilo y hoja en Ugni molinae
}

\author{
In vitro induction of callogenesis and indirect organogenesis from explants of cotyledon, \\ hypocotyl and leaf in Ugni molinae
}

\section{Mario M Rodríguez Beraud a*, Mirtha I Latsague Vidal b, Manuel A Chacón Fuentesa ${ }^{\text {, }}$ Pamela K Astorga Brevis ${ }^{\text {a }}$}

\author{
*Autor de correspondencia: ${ }^{\text {a }}$ Universidad Católica de Temuco, Facultad de Recursos Naturales, Escuela de Agronomía, \\ Temuco, Chile, tel.: 5645 2205536, marodrig@uct.cl \\ b Universidad Católica de Temuco, Facultad de Recursos Naturales, Escuela de Ciencias Ambientales, Temuco, Chile.
}

\begin{abstract}
SUMMARY
The objective of this study was to stimulate the production of calluses, to observe its typologies and organogenic response under different induction and differentiation mediums in explants from cotyledons, hypocotyls and leaves of Ugni molinae. Higher callus production was obtained with cotyledons in a Murashige and Skoog (MS) medium supplemented with $0.5 \mathrm{mg} \mathrm{L}^{-1}$ of naphthaleneacetic acid (NAA), similar also in explants of hypocotyls with 1.0 and $5.0 \mathrm{mg} \mathrm{L}^{-1}$ of NAA, and in the control (62, 62, 74 and $64 \%$, respectively). Larger sizes of calluses were observed in cotyledons and smaller in leaves. Later, calluses were transferred to subcultures without growth regulators, where they were observed green, friable, compact and phenolic, obtaining the higher survival rates in calluses induced with $0.5 \mathrm{mg} \mathrm{L}^{-1}$ of NAA for cotyledon and hypocotyl, and $1.0 \mathrm{mg} \mathrm{L}^{-1}$ of NAA in leaf. Finally, the calluses derived from these treatments were cultivated in a differentiation medium with different concentrations of NAA plus 6-benzylaminopurine (BAP). The best organogenic responses were achieved with cotyledons in a medium without growth regulators and the rhizogenic in leaves with $0.1 \mathrm{mg} \mathrm{L}^{-1}$ of NAA $+1.0 \mathrm{mg} \mathrm{L}^{-1}$ of BAP. These results indicate that it is possible to stimulate different types of calluses and to obtain roots or shoots in $U$. molinae, which makes it possible to potentially use this technique for the conservation, micro-propagation and plants breeding of an endemic plant species.
\end{abstract}

Key words: callogenesis, organogenesis, auxins, cytokinins, Myrtaceae.

\section{RESUMEN}

El objetivo de este estudio fue estimular la producción de callos, observar su tipología y respuesta organogénica bajo diferentes medios de inducción y de diferenciación en explantes de cotiledón, hipocótilo y hoja de Ugni molinae. Los mayores porcentajes de callos se lograron con cotiledones en un medio Murashige y Skoog (MS) suplementado con 0,5 $\mathrm{mg} \mathrm{L}^{-1}$ de ácido naftalenacético (ANA), como también en explantes de hipocótilo con 1,0 y 5,0 $\mathrm{mg} \mathrm{L}^{-1}$ de ANA, además del testigo (62, 62, 74 y 64 \%, respectivamente). El mayor tamaño de callos se observó en cotiledones y el menor en hojas. Posteriormente, los callos fueron transferidos a un subcultivo sin reguladores de crecimiento, donde se observaron callos verdes, friables, compactos y fenólicos, obteniendo la mayor sobrevivencia en callos inducidos con 0,5 $\mathrm{mg} \mathrm{L}^{-1}$ de ANA para cotiledón e hipocótilo y 1,0 $\mathrm{mg} \mathrm{L}^{-1}$ de ANA en hoja. Finalmente, los callos derivados de estos tratamientos fueron cultivados en un medio de diferenciación con distintas concentraciones de ANA más 6-bencilaminopurina (BAP). La mayor respuesta caulogénica se logró en callos de cotiledones en un medio sin reguladores de crecimiento y la rizogénica en callos de hojas con 0,1 $\mathrm{mg} \mathrm{L}^{-1}$ de ANA + 1,0 $\mathrm{mg} \mathrm{L}^{-1}$ de BAP. Estos resultados indican que es posible estimular distintos tipos de callos y obtener raíces o brotes en $U$. molinae, lo que posibilita su uso potencial para la conservación, micropropagación y mejoramiento vegetal de una especie endémica.

Palabras clave: callogénesis, organogénesis, auxinas, citoquininas, Myrtaceae.

\section{INTRODUCCIÓN}

Murta, mutilla o murtilla (Ugni molinae Turcz) es un arbusto endémico de Chile, perteneciente a la familia de las mirtáceas, muy polimorfo, que se desarrolla en forma silvestre en el sur de Chile, entre la región del Maule hasta el río Palena de la región de Aysén. Se lo encuentra tanto en la Cordillera de la Costa como en la Cordillera de Los Andes y en tipos forestales roble-raulí-coihue, coihue-raulí-tepa, roble-hualo y ciprés de Las Guaitecas (Hoffmann 2005). Pese a la gran variabilidad observada en $U$. molinae, existen algunos problemas que están presentes en todos los ecotipos y que impiden la producción comercial de sus frutos, especialmente, su exportación como fruto fresco, como la presencia de sépalos prominentes, semillas duras y cicatriz peduncular (Rodríguez 2000, 2011). El cultivo de callos 
puede ser utilizado para diferentes propósitos, tales como la micropropagación y el mejoramiento vegetal. La producción de callo requiere de un explante inicial, el que puede tener una alta diferenciación de sus tejidos, como un trozo de raíz, tallo u hoja, o bien la utilización de tejidos menos diferenciados como hipocótilos y cotiledones de plántulas recién germinadas e incluso embriones zigóticos maduros e inmaduros (Correia y Canhoto 2010). También, aunque con menor frecuencia, se han utilizado tejidos florales como estambres, pétalos y ovarios (Stefanello et al. 2005). En cualquier caso, la inducción de callo representa un proceso de desdiferenciación y división celular intensiva, el cual depende principalmente del explante, genotipo, medio de cultivo, tipo de regulador de crecimiento como también su concentración y combinación (Larson et al. 2006, Feeney et al. 2007, Rashmi y Trivedi 2014).

La organogénesis indirecta a menudo induce la variación somaclonal y permite exponer características diferentes que no están expresadas normalmente en la naturaleza o bien eliminar alguna indeseable (Sala y Labra 2003). Por otra parte, la rizogénesis in vitro y el cultivo de células a partir de callos podría ser utilizada para la producción de metabolitos secundarios en bioreactores, lo cual resulta interesante para una planta a la cual se le atribuyen numerosas características medicinales, como efectos analgésicos, anti-inflamatorios, astringentes, actividad antimicrobiana y antioxidante de sus hojas (Delporte et al. 2007). Por otra parte, los callos pueden ser utilizados para hacer suspensiones celulares para la producción de embriones somáticos. Normalmente, esta vía requiere de una elevada concentración de auxinas en la etapa de inducción de callo (Trabelsi et al. 2010).

En mirtáceas la producción de callos a partir de tejidos juveniles como embriones zigóticos o parte de plántulas se ha utilizado para la embriogénesis somática indirecta, induciendo callos con diferentes concentraciones y combinaciones de auxinas y citoquininas (Correia y Canhoto 2010, Prakash y Gurumurthi 2010). La caulogénesis indirecta para fines de micropropagación se ha logrado con el uso de citoquininas, principalmente BAP durante la etapa de inducción de callos de Eucalyptus globulus Labill. (Larson et al. 2006) y de Eucalyptus erythronema Turcz. (Glocke et al. 2006). Otra aplicación para el cultivo de callos es la transformación genética mediada por Agrobacterium tumefaciens, o bombardeo con partículas de tungsteno (Al Abdallat et al. 2011).

La callogénesis de $U$. molinae no ha sido reportada, lo cual es la base para la aplicación de otras técnicas mencionadas anteriormente. Las hipótesis de esta investigación son que Ugni molinae es capaz de formar callos a partir de explantes de cotiledón, hipocótilos y hojas y que es posible obtener una respuesta organogénica a partir de estos callos. Los objetivos son inducir la formación de callo en explantes de cotiledones, hipocótilos y hojas, describir su tipología y posterior diferenciación organogénica bajo diferentes tratamientos de reguladores de crecimiento como 2,4 diclorofenoxiacético (2,4-D), ácido naftalenacético (ANA) y 6-bencilaminopurina (BAP).

\section{MÉTODOS}

El ensayo se realizó en el laboratorio de Cultivo de Tejidos Vegetales de la Facultad de Recursos Naturales, Escuela de Agronomía de la Universidad Católica de Temuco, región de La Araucanía, Chile. Todos los medios de cultivo utilizados en la presente investigación fueron gelificados con $7 \mathrm{~g} \mathrm{~L}^{-1}$ de agar y se esterilizaron en autoclave a $120^{\circ} \mathrm{C}$ a 1 atmósfera de presión (0,1 MPa) por 20 minutos. Las placas Petri desechables de 60 x $15 \mathrm{~mm}$ contenían $10 \mathrm{~mL}$ de medio cada una, el pH fue ajustado a 5,8 con 1,0 N hidróxido de potasio $(\mathrm{KOH})$ y $1,0 \mathrm{~N}$ de ácido clorhídrico $(\mathrm{HCl})$. Las condiciones de incubación fueron $25{ }^{\circ} \mathrm{C} \pm 1$, fotoperiodo de $16 \mathrm{~h}$ luz con 3.000 lux de intensidad (tubos Philips TLD 36W/54).

Material vegetal. Para la obtención de explantes de cotiledón, hipocótilos y hojas se germinaron in vitro semillas de $U$. molinae cosecha 2009, procedentes de la localidad de Curiñanco, sector costero de Valdivia, zona sur de Chile (latitud $39^{\circ} 40^{\prime} \mathrm{S}$, longitud $73^{\circ} 21^{\prime} \mathrm{O}$ ). Las semillas fueron desinfectadas en cámara de flujo laminar con una solución de fungicida ( $2 \mathrm{~g} \mathrm{~L}^{-1}$ de Mancozeb $+0,6 \mathrm{~g} \mathrm{~L}^{-1}$ de Benomil), más unas gotas de tensoactivo Tween 20 por 20 minutos. Luego, se adicionó hipoclorito de sodio ( $\mathrm{NaClO})$ al $2 \%$ $\mathrm{v} / \mathrm{v}$ (cloro activo) por 10 minutos y etanol $70^{\circ}$ por 5 segundos, finalizando con tres enjuagues consecutivos de agua destilada estéril. Posteriormente, las semillas fueron secadas en cámara de flujo laminar a $20^{\circ} \mathrm{C}$ durante $24 \mathrm{~h}$ y almacenadas a $4{ }^{\circ} \mathrm{C}$ por cinco meses. Se sembraron 25 semillas por placa Petri, la germinación in vitro se realizó en un medio (agua y agar) de $\mathrm{pH}$ 5,8 aplicando como buffer $3 \mathrm{mM} \mathrm{L}^{-1}$ de ácido 2-(N-morfolino) etano sulfónico (MES). A los siete días de germinadas se escindieron los cotiledones e hipocótilos de las plántulas. Otro grupo de semillas continuó su desarrollo hasta cuatro semanas para la obtención de hojas con pecíolo, las que se colocaron en forma abaxial en contacto con el medio.

Callogénesis. Para la inducción de callos, los explantes se cultivaron en un medio MS (Murashige y Skoog 1962), suplementando con $30 \mathrm{~g} \mathrm{~L}^{-1}$ de sacarosa más ácido 2,4 diclorofenoxiacético (2,4-D) o ácido naftalenacético (ANA), o la auxina en combinación con 6-bencilaminopurina (BAP), más un testigo por explante (cuadro 1). Este ensayo se mantuvo en oscuridad continua por 21 días. Al finalizar esta etapa, se evaluó la callogénesis y se clasificó por tamaño de callos. La callogénesis se expresa como el porcentaje de explantes que forman callos. Posterior a la inducción, los callos de los diferentes explantes fueron transferidos a un medio de cultivo MS, sin reguladores de crecimiento, suplementado con $30 \mathrm{~g} \mathrm{~L} \mathrm{~L}^{-1}$ de sacarosa y mantenidos durante 60 días en cámara de incubación, con un fotoperiodo de 16 h luz. Se realizaron dos subcultivos con intervalos de 30 días. Finalizada esta etapa se evaluó la sobrevivencia de callos y se clasificaron en verde, friable, compacto y fenólico. 
Organogénesis. Los callos procedentes del subcultivo, fueron repicados a un tamaño aproximado de $0,3 \mathrm{~cm}$ cada uno, excepto los más pequeños, y transferidos a placas Petri con un medio basal MS suplementado con diferentes combinaciones hormonales, para su diferenciación (cuadro 2). Los medios de cultivos fueron suplementados con $30 \mathrm{~g} \mathrm{~L}^{-1} \mathrm{de}$ sacarosa y mantenidos durante 21 días en cámara de incubación con un fotoperiodo de $16 \mathrm{~h}$ luz. Al finalizar este período se midió longitud y porcentaje de brotes y raíces.

Estudio morfológico. Se efectuaron análisis morfológicos con una lupa Japan Optical CO. Modelo XTL-2310 (10 x 4,5 ), para diferenciar estructuras callogénicas y organogénicas, bajo condiciones asépticas. Se realizaron caracterizaciones que incluyeron aspectos tales como, tamaño, co-

Cuadro 1. Tratamientos de inducción de callos en medio MS. Treatments for callus induction in MS medium.

\begin{tabular}{|c|c|c|}
\hline Tratamiento & Explante & Medio de inducción $\left(\mathrm{mg} \mathrm{L}^{-1}\right)$ \\
\hline 1 & Cotiledón & $2,4-\mathrm{D} 0,5$ \\
\hline 2 & Cotiledón & $2,4-\mathrm{D} 1,0$ \\
\hline 3 & Cotiledón & 2,4-D 5,0 \\
\hline 4 & Cotiledón & ANA 0,5 \\
\hline 5 & Cotiledón & ANA 1,0 \\
\hline 6 & Cotiledón & ANA 5,0 \\
\hline 7 & Cotiledón & 2,4-D 1,0 + BAP 1,0 \\
\hline 8 & Cotiledón & ANA $1,0+$ BAP 1,0 \\
\hline 9 (Control 1) & Cotiledón & 0 \\
\hline 10 & Hipocótilo & 2,4-D 0,5 \\
\hline 11 & Hipocótilo & $2,4-\mathrm{D} 1,0$ \\
\hline 12 & Hipocótilo & 2,4-D 5,0 \\
\hline 13 & Hipocótilo & ANA 0,5 \\
\hline 14 & Hipocótilo & ANA 1,0 \\
\hline 15 & Hipocótilo & ANA 5,0 \\
\hline 16 & Hipocótilo & 2,4-D 1,0 + BAP 1,0 \\
\hline 17 & Hipocótilo & ANA $1,0+$ BAP 1,0 \\
\hline 18 (Control 2) & Hipocótilo & 0 \\
\hline 19 & Hoja & $2,4-\mathrm{D} 0,5$ \\
\hline 20 & Hoja & $2,4-\mathrm{D} 1,0$ \\
\hline 21 & Hoja & 2,4-D 5,0 \\
\hline 22 & Hoja & ANA 0,5 \\
\hline 23 & Hoja & ANA 1,0 \\
\hline 24 & Hoja & ANA 5,0 \\
\hline 25 & Hoja & $2,4-\mathrm{D} 1,0+$ BAP 1,0 \\
\hline 26 & Hoja & ANA 1,0 + BAP 1,0 \\
\hline 27 (Control 3) & Hoja & 0 \\
\hline
\end{tabular}

lor, y superficie del callo. Para la cuantificación de tamaño de callos, longitud de brotes y raíces se utilizó un pie de metro digital Mitutoyo CD-6. Como criterio de clasificación de tamaño de callos se utilizó la siguiente escala, callos pequeños $<0,5 \mathrm{~cm}$, callos mediano entre $0,5-1,0 \mathrm{~cm}$ y callos grandes $>1,0 \mathrm{~cm}$.

Diseño experimental y análisis de los datos. Los análisis estadísticos se realizaron mediante el software SPSS (versión 15,0 para Windows). Cada tratamiento constó de 10 placas con cinco explantes cada una, utilizando la placa como unidad experimental, tanto para la etapa de inducción como de diferenciación. Para el ensayo de callogénesis se utilizó un experimento completamente aleatorio con un factorial de $3 \times 9$, producto de tres tipos de explantes y nueve combinaciones hormonales (cuadro 1) y para el ensayo de organogénesis un factorial de $3 \times 3$ producto de tres tipos de explantes y tres combinaciones hormonales (cuadro 2). Se aplicó la prueba de normalidad (Shapiro-Wilk) y se analizó la homogeneidad de varianzas (estadístico de Levene). Para observar las diferencias significativas en los porcentajes de callogénesis en el medio de inducción y la organogénesis en el medio de diferenciación, se utilizó un análisis de varianza (ANDEVA) con un $P \leq 0,05$ y la prueba de comparación múltiple de Tamhane para la formación de grupos. Los datos de porcentajes fueron normalizados usando una transformación mediante el cálculo de arcoseno de la raíz cuadrada del porcentaje.

\section{RESULTADOS}

Callogénesis. El análisis de los factores tipo de explante y combinaciones hormonales indicaron, para ambos, diferencia significativas $(P \leq 0,05)$. Los hipocótilos alcanzaron el promedio más alto de formación de callo respecto a los otros explantes (49\% vs $41 \%$ y $18 \%$ de cotiledones y hojas respectivamente), en tanto que ANA fue el regulador de crecimiento que más estimuló la callogénesis.

Cuadro 2. Tratamientos para organogénesis de callos en medio MS. Treatments for callus organogenesis in MS medium.

\begin{tabular}{ccc}
\hline Tratamiento & Explante & $\begin{array}{c}\text { Medio de diferenciación } \\
\left(\mathrm{mg} \mathrm{L}^{-1}\right)\end{array}$ \\
\hline 1 & Cotiledón & ANA 0,1 + BAP 0,5 \\
2 & Cotiledón & ANA 0,1 + BAP 1,0 \\
3 (Control 1) & Cotiledón & 0 \\
4 & Hipocótilo & ANA 0,1 + BAP 0,5 \\
5 & Hipocótilo & ANA 0,1 + BAP 1,0 \\
$6($ Control 2) & Hipocótilo & 0 \\
7 & Hoja & ANA 0,1 + BAP 0,5 \\
8 & Hoja & ANA 0,1 + BAP 1,0 \\
9 (Control 3) & Hoja & 0 \\
\hline
\end{tabular}


En cotiledones, el aumento de la concentración de ANA produjo una disminución en el porcentaje de callogénesis observándose la mayor respuesta (62 \%) con 0,5 mg L ${ }^{-1}$ de ANA. En general, la combinación de BAP con auxinas disminuyó la formación de callo respecto a la auxina utilizada por sí sola (figura 1). En hipocótilos, los promedios máximos de $74 \%$, $62 \%$, y $64 \%$ de callogénesis se registraron en los tratamientos 5,0 y 1,0 $\mathrm{mg} \mathrm{L}^{-1}$ de ANA y control respectivamente. En tanto, que el promedio más bajo se observó en el tratamiento $1,0 \mathrm{mg} \mathrm{L}^{-1}$ de 2,4-D + 1,0 $\mathrm{mg} \mathrm{L}^{-1}$ de BAP (14 \%). Los hipocótilos tratados con 2,4D o con ANA, presentaron un aumento en el porcentaje de callogénesis, en relación a la concentración hormonal. Respecto a los explantes de hojas, la formación de callo fue baja en comparación con los cotiledones e hipocótilos, el tratamiento que obtuvo el porcentaje más alto de callogénesis fue $1,0 \mathrm{mg} \mathrm{L}^{-1}$ de 2,4-D + 1,0 $\mathrm{mg} \mathrm{L}^{-1}$ de BAP con un $60 \%$, este explante, a diferencia de los demás, presentó mejores respuestas en los tratamientos combinados de auxinas con BAP. Los menores porcentajes se observaron en los tratamientos con 2,4-D y testigo.

Tamaño de los callos. El mayor crecimiento de callos se observó en cotiledones, especialmente los tratados con $0,5 \mathrm{mg}$ $\mathrm{L}^{-1}$ de ANA, luego en orden decreciente, hipocótilos y hojas (cuadro 3). En los explantes de cotiledón prevalecieron los tamaños medianos, a excepción de aquellos que incluyeron BAP, los cuales fueron pequeños. Para hipocótilos, los tratamientos testigo y 2,4-D a concentraciones de 0,5 y $1,0 \mathrm{mg}$ $\mathrm{L}^{-1}$ lograron tamaños de callos medianos, en tanto que el aumento de la concentración de ANA y 2,4-D produjo callos pequeños. Los tratamientos de auxinas en combinación con BAP solo produjeron callos pequeños en todos los explantes.
Tipos de callos. Luego de una etapa de inducción y de subcultivo sin reguladores de crecimiento, algunos callos no sobrevivieron, especialmente los provenientes de hojas (cuadro 4). Los callos presentaron contrastes morfológicos evidentes respecto a su color, textura y superficie clasificándose en cuatro tipos (figura 2). Los porcentajes más altos de callos verdes se alcanzaron en hipocótilos y cotiledones procedentes del testigo con un $40 \%$ en ambos (figura 2A y 2E), como también en callos de hojas (46\%)

Cuadro 3. Tamaño de los callos (cm) en explantes de cotiledón, hipocótilo y hoja de Ugni molinae a los 21 días de cultivo en medio MS bajo tratamiento de inducción.

Size of the callus of Ugni molinae after 21 days in MS induction medium in explants of cotyledon, hypocotyl and leaf.

\begin{tabular}{ccccccc}
\hline \multicolumn{3}{c}{ Hormona $\left(\mathrm{mg} \mathrm{L}^{-1}\right)$} & & \multicolumn{4}{c}{ Tamaño de callo } \\
\cline { 1 - 2 } \cline { 5 - 6 } Auxina & Citoquinina & & Cotiledón & Hipocótilo & Hoja \\
\hline- & - & ++ & ++ & + \\
$2,4-D$ 0,5 & - & ++ & ++ & + \\
2,4-D 1,0 & - & ++ & ++ & + \\
2,4-D 5,0 & - & ++ & + & + \\
ANA 0,5 & - & & ++ & ++ & + \\
ANA 1,0 & - & & ++ & + & + \\
ANA 5,0 & - & & ++ & + & + \\
2,4-D 1,0 & BAP 1,0 & + & + & + \\
ANA 1,0 & BAP 1,0 & + & + & + \\
\hline
\end{tabular}

Tamaño de callos: + pequeños $<0,5 \mathrm{~cm},++$ medianos $0,5-1,0 \mathrm{~cm},+++$ grandes $>1,0 \mathrm{~cm} ; \mathrm{n}=10$.

Sobre el $70 \%$ de los datos, se encuentran en los rangos asignados.

Cuadro 4. Sobrevivencia y tipos de callo obtenidos de diferentes explantes de Ugni molinae, a los 60 días en subcultivo en medio MS sin reguladores de crecimiento.

Survival rates and types of calluses of different explants from Ugni molinae, after 60 days in subculture in the MS medium without growth regulators.

\begin{tabular}{|c|c|c|c|c|c|c|c|c|c|c|c|c|c|c|c|}
\hline \multirow{2}{*}{$\begin{array}{l}\text { Procedencia del } \\
\text { tratamiento }\left(\mathrm{mg} \mathrm{L}^{-1}\right)\end{array}$} & \multicolumn{3}{|c|}{$\begin{array}{l}\text { Sobrevivencia de } \\
\text { callos (\%) }\end{array}$} & \multicolumn{3}{|c|}{$\begin{array}{c}\text { Callo verde } \\
\text { (\%) }\end{array}$} & \multicolumn{3}{|c|}{$\begin{array}{c}\text { Callo friable } \\
(\%)\end{array}$} & \multicolumn{3}{|c|}{$\begin{array}{c}\text { Callo compacto } \\
(\%)\end{array}$} & \multicolumn{3}{|c|}{$\begin{array}{l}\text { Callo fenólico } \\
\text { (\%) }\end{array}$} \\
\hline & $\mathrm{C}^{*}$ & $\mathrm{Hi}^{*}$ & $\mathrm{H}^{*}$ & $\mathrm{C}$ & $\mathrm{Hi}$ & $\mathrm{H}$ & $\mathrm{C}$ & $\mathrm{Hi}$ & $\mathrm{H}$ & $\mathrm{C}$ & $\mathrm{Hi}$ & $\mathrm{H}$ & $\mathrm{C}$ & $\mathrm{Hi}$ & $\mathrm{H}$ \\
\hline Testigo & 56 & 74 & 0 & 40 & 40 & 0 & 10 & 6 & 0 & 0 & 0 & 0 & 6 & 28 & 0 \\
\hline 2,4-D 0,5 & 34 & 58 & 0 & 0 & 0 & 0 & 6 & 0 & 0 & 28 & 52 & 0 & 0 & 6 & 0 \\
\hline $2,4-\mathrm{D} 1,0$ & 48 & 78 & 0 & 0 & 0 & 0 & 18 & 12 & 0 & 30 & 38 & 0 & 0 & 28 & 0 \\
\hline 2,4-D 5,0 & 56 & 70 & 0 & 2 & 0 & 0 & 28 & 28 & 0 & 0 & 0 & 0 & 26 & 42 & 0 \\
\hline ANA 0,5 & 72 & 94 & 0 & 0 & 0 & 0 & 38 & 20 & 0 & 34 & 0 & 0 & 0 & 74 & 0 \\
\hline ANA 1,0 & 48 & 64 & 80 & 0 & 0 & 46 & 34 & 26 & 34 & 0 & 0 & 0 & 14 & 38 & 0 \\
\hline ANA 5,0 & 50 & 74 & 16 & 0 & 0 & 4 & 24 & 28 & 6 & 0 & 0 & 2 & 26 & 46 & 4 \\
\hline $2,4-\mathrm{D} 1,0+\mathrm{BAP} 1,0$ & 26 & 6 & 0 & 0 & 0 & 0 & 24 & 2 & 0 & 0 & 0 & 0 & 2 & 4 & 0 \\
\hline ANA $1,0+$ BAP 1,0 & 74 & 30 & 0 & 0 & 0 & 0 & 72 & 22 & 0 & 0 & 0 & 0 & 2 & 8 & 0 \\
\hline
\end{tabular}

* C = cotiledón, $\mathrm{Hi}$ = hipocótilo, $\mathrm{H}$ = hoja. 


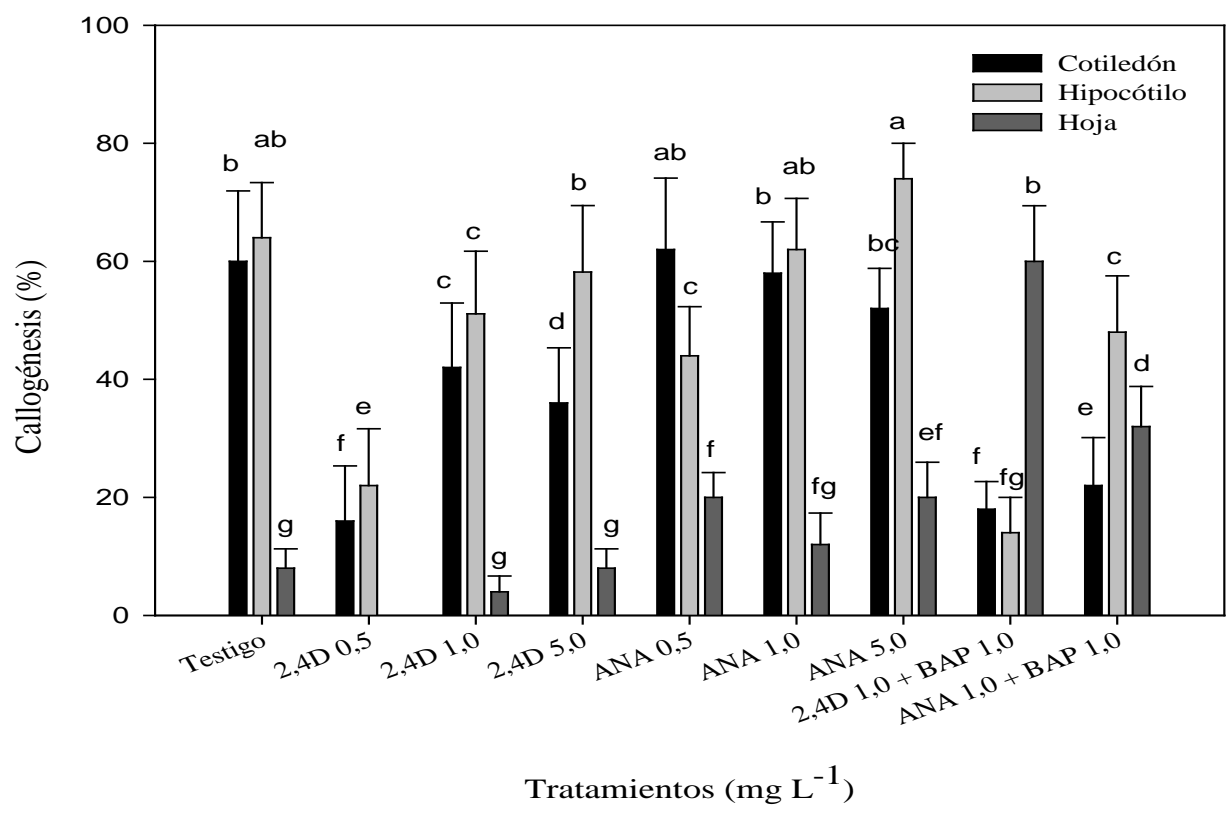

Figura 1. Respuestas callogénicas (\%) para los diferentes medios de inducción en explantes de cotiledón, hipocótilo y hoja a los 21 días. Barras y líneas verticales representan el promedio \pm el error estándar de la media. Barras con letras distintas indican diferencias significativas (Tamhane, ${ }^{*} P \leq 0,05, \mathrm{n}=10$ ).

Callogenic responses (\%) for different induction media in explants of cotyledons, hypoctyls and leaves after 21 days. Bars and vertical lines represent average and the standard error. Bars with different letters indicate significant differences among means (Tamhane, ${ }^{*} P \leq 0.05, \mathrm{n}=10$ ).

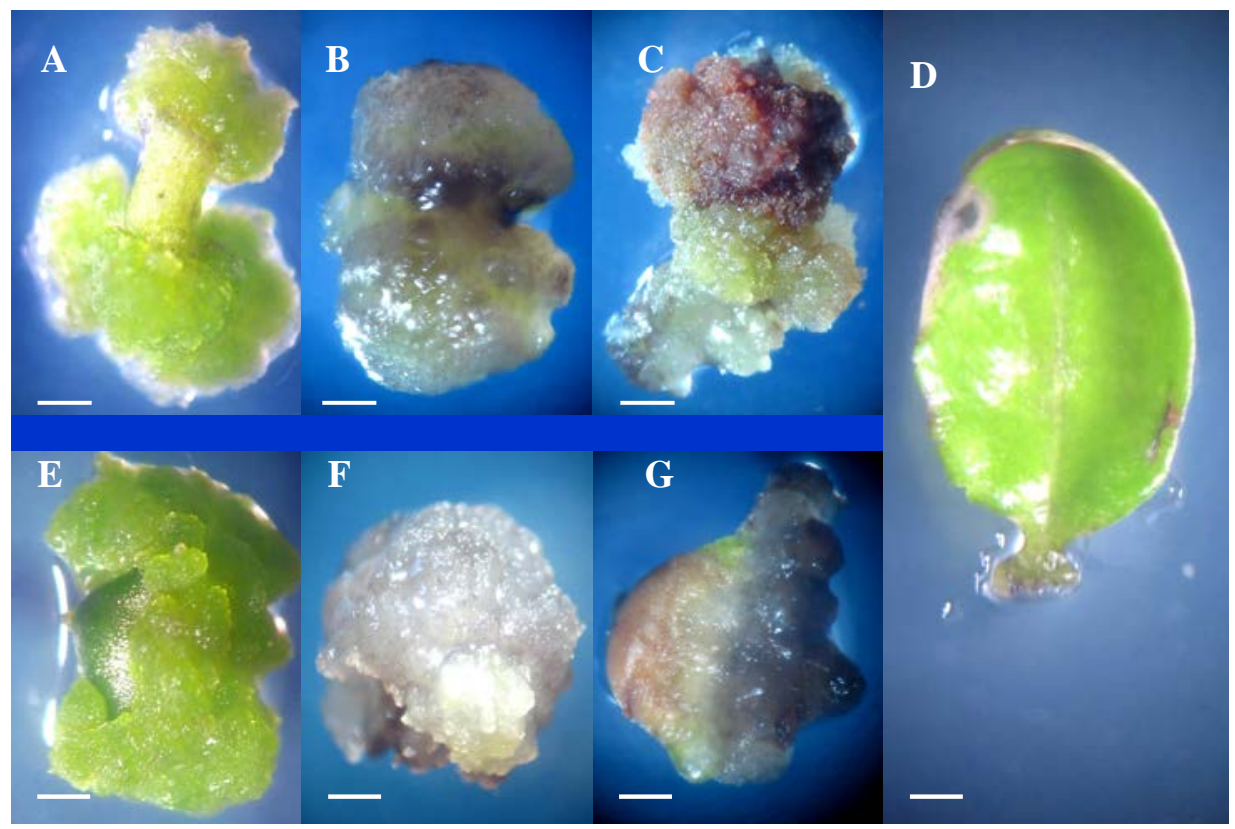

Figura 2. Tipos de callos en Ugni molinae, a partir de distintos explantes procedentes de 21 días en medios de inducción y 60 días de subcultivo en medio MS sin reguladores de crecimiento. Hipocótilos (A) Callo verde testigo. (B) Callo compacto 0,5 mg $\mathrm{L}^{-1}$ de 2,4 diclorofenoxiacético (2,4-D). (C) Callo fenólico 0,5 $\mathrm{mg} \mathrm{L}^{-1}$ ácido naftalenacético (ANA). Hoja (D) Callo verde 1,0 mg L-1 ANA. Cotiledones (E) Callo verde testigo. (F) Callos friable 1,0 $\mathrm{mg} \mathrm{L}^{-1} \mathrm{ANA}+1,0 \mathrm{mg} \mathrm{L}^{-1}$ de 6-bencilaminopurina (BAP). (G) Callo fenólico $5,0 \mathrm{mg} \mathrm{L}^{-1}$ de ANA. Barras corresponden a $0,1 \mathrm{~cm}$.

Types of calluses in Ugni molinae, from different explants after 21 days in induction medium and 60 days of subculturing in the MS medium without growth regulators. Hypocotyls (A) Green callus, control. (B) Compact callus, $0.5 \mathrm{mg} \mathrm{L}^{-1}$ of 2.4 diclorofenoxiacetic (2.4-D). (C) Phenolic callus, $0.5 \mathrm{mg} \mathrm{L}^{-1}$ naftalenacetic acid (NAA). Leaves (D) Green callus, $1.0 \mathrm{mg} \mathrm{L}^{-1} \mathrm{NAA}$. Cotyledons (E) Green callus, control. (F) Friable callus, NAA + 1.0 $\mathrm{mg} \mathrm{L}^{-1}$ of 6-bencilaminopurine (BAP). (G) Phenolic callus, NAA $5.0 \mathrm{mg} \mathrm{L}^{-1}$. Bars correspond to $0.1 \mathrm{~cm}$. 
derivados del medio de inducción con 1,0 mg L $\mathrm{L}^{-1} \mathrm{ANA}$ (figura 2D). En tanto, el máximo para callos friables (72 \%) se logró sobre cotiledones procedentes del tratamiento con $1,0 \mathrm{mg} \mathrm{L}^{-1}$ de ANA $+1,0 \mathrm{mg} \mathrm{L}^{-1}$ de BAP (figura 2F). Los callos compactos alcanzaron su máxima respuesta (52\%) en hipocótilos tratados con 0,5 $\mathrm{mg} \mathrm{L}^{-1} \mathrm{de}$ 2,4-D (figura 2B). Respecto a los callos fenólicos, el mayor porcentaje (74 \%) se presentó en hipocótilos, particularmente en los tratados con $0,5 \mathrm{mg} \mathrm{L}^{-1}$ de ANA (figura $2 \mathrm{C}$ ) y en cotiledones con $0,5 \mathrm{mg} \mathrm{L}^{-1}$ de 2,4 D y 5,0 $\mathrm{mg} \mathrm{L}^{-1}$ de ANA (figura $2 \mathrm{G}$ ).

Caulogénesis. La formación de brotes en callos fue baja, siendo nula para el caso de los explantes de hojas (cuadro 5). Los porcentajes más altos de caulogénesis se obtuvieron en los tratamientos testigo y $0,1 \mathrm{mg} \mathrm{L}^{-1}$ de ANA $+1,0 \mathrm{mg} \mathrm{L}^{-1}$ de BAP con un $6 \%$ y $4 \%$, respectivamente, ambos en cotiledones (figura 3A). En relación al largo del brote, se obtuvieron las mayores longitudes en los tratamientos $0,1 \mathrm{mg} \mathrm{L}^{-1}$ de ANA $+1,0 \mathrm{mg} \mathrm{L}^{-1}$ de BAP con 1,35 cm en cotiledones y $0,1 \mathrm{mg} \mathrm{L}^{-1}$ de ANA + 0,5 mg L $\mathrm{L}^{-1}$ de BAP con 1,45 cm en hipocótilos.

Rizogénesis. Se observó formación de raíces en todos los tratamientos excepto en los cotiledones sin reguladores de crecimiento. Las hojas presentaron la mayor respuesta (32 \%) en la combinación hormonal con mayor concentración de BAP (figura 3D), a diferencia de los otros explantes que obtuvieron una mayor rizogénesis con una baja concentración de BAP (figura 3B y 3 C).

Con respecto al largo de las raíces, en cotiledones la mayor longitud se alcanzó con el tratamiento $0,1 \mathrm{mg} \mathrm{L}^{-1} \mathrm{de}$

Cuadro 5. Respuesta organogénica, longitud de brotes y raíces de Ugni molinae a los 21 días en medio de diferenciación (MS).

Organogenic responses of Ugni molinae, length of shoots and roots after 21 days in the differentiation medium (MS).

\begin{tabular}{|c|c|c|c|c|}
\hline \multirow{2}{*}{$\begin{array}{l}\text { Tratamientos } \\
\left(\mathrm{mg} \mathrm{L}^{-1}\right)\end{array}$} & \multicolumn{2}{|c|}{ Organogenesis (\%) } & \multicolumn{2}{|c|}{ Longitud $(\mathrm{cm})$} \\
\hline & Brote & Raíz & Brote & Raíz \\
\hline \multicolumn{5}{|c|}{ Explante cotiledón } \\
\hline Testigo & $6^{\mathrm{a}}$ & 0 & $0,85^{\mathrm{bc}}$ & 0,00 \\
\hline ANA $0,1+$ BAP 0,5 & 0 & $20^{\mathrm{b}}$ & 0,00 & $3,60^{\mathrm{d}}$ \\
\hline ANA $0,1+$ BAP 1,0 & $4^{\mathrm{ab}}$ & $6^{\mathrm{cd}}$ & $1,35^{\mathrm{ab}}$ & $5,85^{c}$ \\
\hline \multicolumn{5}{|c|}{ Explante hipocótilo } \\
\hline Testigo & 0 & $8^{c}$ & 0,00 & $6,08^{\text {bc }}$ \\
\hline ANA $0,1+$ BAP 0,5 & $2^{\mathrm{b}}$ & $16^{\mathrm{b}}$ & $1,45^{\mathrm{a}}$ & $13,20^{\mathrm{a}}$ \\
\hline ANA $0,1+$ BAP 1,0 & $2^{\mathrm{b}}$ & $10^{c}$ & $0,55^{c}$ & $3,14^{\mathrm{d}}$ \\
\hline \multicolumn{5}{|c|}{ Explante hoja } \\
\hline Testigo & 0 & $2^{\mathrm{d}}$ & 0,00 & $8,90^{b}$ \\
\hline ANA $0,1+$ BAP 0,5 & 0 & $4^{\mathrm{d}}$ & 0,00 & $2,65^{\mathrm{d}}$ \\
\hline ANA $0,1+$ BAP 1,0 & 0 & $32^{\mathrm{a}}$ & 0,00 & $4,87^{\mathrm{cd}}$ \\
\hline
\end{tabular}

Medias dentro de cada columna con letras distintas indican diferencias significativas (Tamhane, $*=P \leq 0,05, \mathrm{n}=10$ ).
ANA + 1,0 mg L-1 de BAP con 5,85 cm, para hojas en el testigo con 8,9 cm y en hipocótilos con $0,1 \mathrm{mg} \mathrm{L}^{-1}$ de ANA + 0,5 $\mathrm{mg} \mathrm{L}^{-1}$ de BAP observándose en este tratamiento el promedio de $13,20 \mathrm{~cm}$, siendo este último valor significativamente $(P \leq 0,05)$ el más alto para esta variable.

\section{DISCUSIÓN}

$\mathrm{Al}$ menos el $60 \%$ de los cotiledones e hipocótilos de $U$. molinae son capaces de formar callos en un medio MS prescindiendo de auxinas o de combinaciones de éstas con BAP (figura 1). Esta respuesta es poco frecuente, ya que generalmente la formación de callo es estimulada por el corte de los tejidos y la concentración exógena del regulador de crecimiento utilizado. Los callos se generan a partir de la zona de corte en todos los explantes (figura 2), los hipocótilos lo hacen en ambos extremos y las hojas en la base del pecíolo lo que sugiere una acumulación de auxinas en las zonas de corte y en consecuencia una estimulación de la mitosis permitiendo la formación de tejido calloso (Smith 2012).

La callogénesis es altamente dependiente del tipo de explante y hormona utilizada. En hipocótilos, a diferencia de los otros explantes, se ve un claro incremento de la callogénesis cuando se aumenta la concentración de 2,4-D y ANA (figura 1). Entre los tratamientos que utilizaron las auxinas con BAP la mejor combinación es ANA + BAP tanto en cotiledón como en hipocótilo, al igual que lo observado por Gómez et al. (2006) en E. globulus. En hojas, en contraste a hipocótilos y cotiledones, la callogénesis responde a la presencia de BAP en los medios de inducción, especialmente, cuando se combina con 2,4-D superando el porcentaje del testigo. Al respecto, Pinto et al. (2002) lograron incrementar el porcentaje de callos aumentando la concentración hormonal de 2,4-D y de BAP en este tipo de explantes en E. globulus.

El tamaño de callos en cotiledones de $U$. molinae es en general superior al de hipocótilo y hoja (cuadro 3), como lo observado por Pinto et al. (2002) al utilizar 2,4-D y ANA en E. globulus, sin embargo, resulta inferior al reporte de Gómez et al. (2006) quienes observaron tamaños promedios de $1,5 \mathrm{~cm}$ en combinaciones de 2,4-D y BAP.

Tanto los callos verdes como los fenólicos presentaron una superficie nodular. Muchos investigadores han relacionado el tipo de callo con la respuesta organogénica y embriogénica que se pueda presentar, siendo altamente dependiente de la especie. Por lo tanto, el tipo de callo puede ser un indicador importante de la ruta morfogénica a seguir (Smith 2012). No obstante, independiente del color del callo existe una alta evidencia que los callos organogénicos proceden, generalmente, de callos nodulares ya sean de color verde o de apariencia oxidada como los fenólicos (Bandyopadhyay et al. 1999, Ainsley et al. 2000). El pardeamiento de los callos fenólicos fue en aumento en relación a los días de cultivo, en algunos casos especialmente los que detuvieron su crecimiento quedaron finalmente ne- 


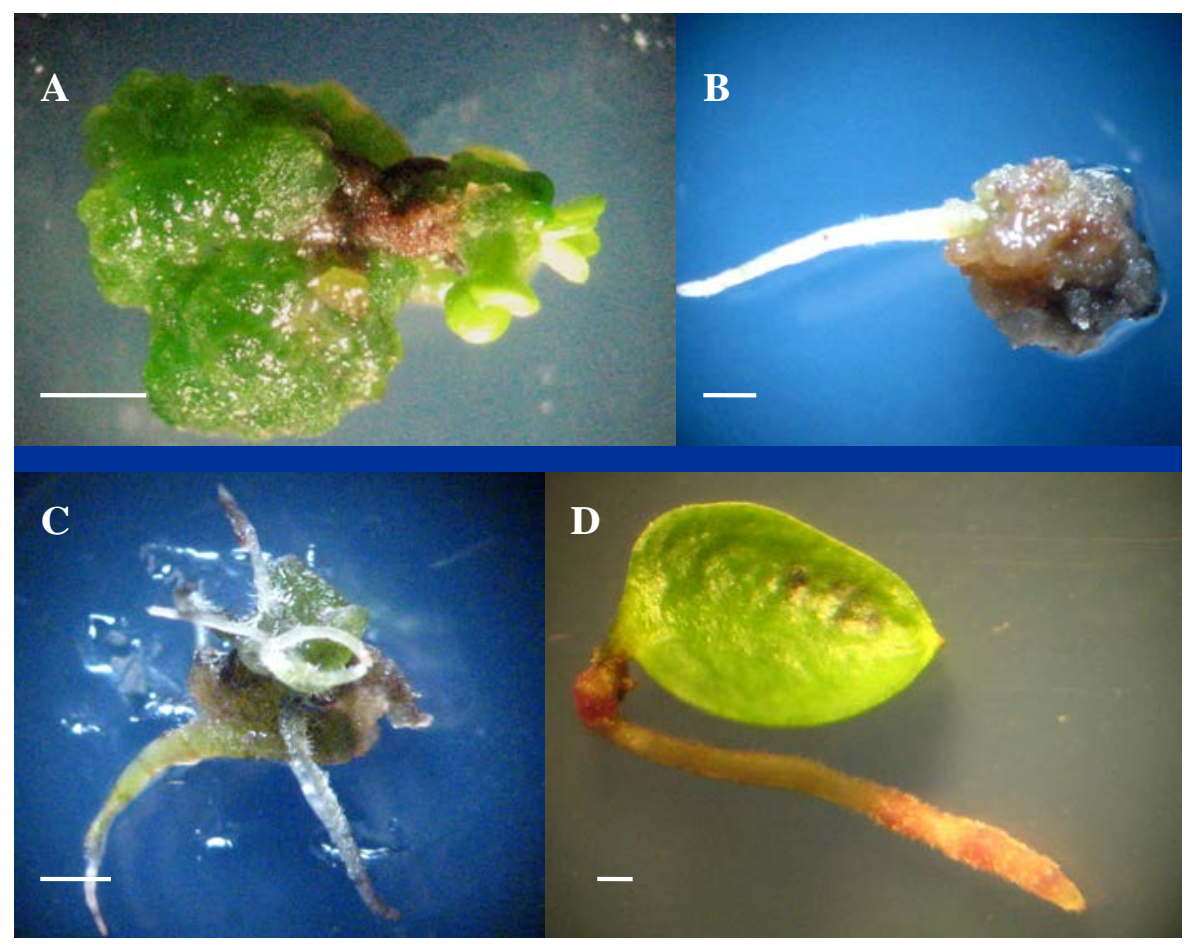

Figura 3. Respuesta organogénica del cultivo de callos de Ugni molinae en medios de diferenciación. A) Caulogénesis a partir de callo de cotiledón obtenido de un medio MS sin reguladores de crecimiento. B) Rizogénesis sobre callos de cotiledón cultivados en MS + 0,1 $\mathrm{mg} \mathrm{L}^{-1}$ de ácido naftalenacético (ANA) + 0,5 $\mathrm{mg} \mathrm{L}^{-1}$ de 6-bencilaminopurina (BAP). C) Rizogénesis sobre callos de hipocótilo en medio MS + 0,1 mg L $\mathrm{m}^{-1} \mathrm{ANA}+0,5 \mathrm{mg} \mathrm{L}^{-1}$ BAP. D) Rizogénesis a partir de callo sobre el pecíolo de la hoja en un medio MS + 0,1 mg $\mathrm{L}^{-1} \mathrm{ANA}+1,0 \mathrm{mg} \mathrm{L^{-1 }}$ BAP. Barras corresponden a $0,1 \mathrm{~cm}$.

Organogenic responses from calluses culture of Ugni molinae in differentiation medium. A) Caulogenesis from callus of cotyledons obtained of MS medium without growth regulators. B) Rizogenesis from cotyledons calluses cultivated in MS $+0.1 \mathrm{mg} \mathrm{L}^{-1}$ of naftalenacetic acid (NAA) + $0.5 \mathrm{mg} \mathrm{L}^{-1}$ of 6-bencilaminopurine (BAP). C) Rizogenesis from hypocotyls calluses in medium MS + $0.1 \mathrm{mg} \mathrm{L}^{-1} \mathrm{NAA}+0.5 \mathrm{mg} \mathrm{L}^{-1} \mathrm{BAP}$. D) Rizogenesis from calluses on petiole leaf calluses in medium MS + $0.1 \mathrm{mg} \mathrm{L}^{-1} \mathrm{NAA}+1.0 \mathrm{mg} \mathrm{L}^{-1} \mathrm{BAP}$. Bars correspond to $0.1 \mathrm{~cm}$.

cróticos y otros continuaron hacia la formación de órganos (figura 3). El cambio de aspecto de los callos conforme se cultivan en el tiempo ha sido reportado por Larson et al. (2006). La apariencia translúcida, cristalina y superficie lisa de los callos compactos de $U$. molinae se relaciona a los explantes de cotiledón e hipocótilos inducidos con 2,4-D. Al respecto Shiram et al. (2008) señalan que altas concentraciones de auxina o citoquininas estimulan la producción de callo y que su aspecto está relacionado al tipo de hormona utilizada durante su inducción.

Después de 21 días en medios de inducción en base a auxinas, 60 días previos de subcultivo de callos en un medio MS sin hormonas y 21 días en medios de diferenciación con mayor relación citoquinina/auxina se observó una rizogénesis predominante para todos los tratamientos ensayados, excepto, en los cotiledones no tratados con hormonas. Lo anterior puede ser atribuido a la mayor presencia de auxinas en los medios de inducción de callo en este estudio. La presencia de brotes en cotiledones e hipocótilos en $U$. molinae, aunque es baja, sugiere que si el objetivo es la regeneración indirecta de plantas se debe inducir callos a partir de estos explantes sin hormonas o a base del uso de citoquininas como BAP, zeatina (ZEA), kinetina (KIN) o tiadizuron (TDZ) (Larson et al. 2006, Meiners et al. 2007). Se observó además que, durante el transcurso de formación de brotes, los callos que dieron origen a brotes fueron aumentando su grado de oxidación, situación también descrita por Gómez et al. (2006) y Feeney et al. (2007), la cual se atribuye a la producción de fenoles. La caulogénesis dependería de una relación óptima entre las concentraciones totales de citoquininas y de auxinas exógenas y endógenas. La formación de raíces generalmente se opone a la formación de vástagos y viceversa, si ambos procesos se intentan de forma simultánea in vitro frecuentemente se producen problemas (Smith 2012). No obstante, en otras investigaciones la inducción de callos con una alta relación auxina/ citoquinina o sólo auxinas favorece la presencia de callos caulogénicos, como lo dejan en evidencia los reportes de Tang y Newton (2005) en Pinus strobus L. y de Hajari et al. (2006) en híbridos de Eucalyptus grandis x Eucalyptus urophylla. En otros casos, como en Eucaliptus nitens, E. globulus y E. camaldulensis, la inducción basada en auxinas ha promovido callos embriogénicos (Bandyopadhyay et al. 1999, Prakash y Gurumurthi 2010). Este estudio, pio- 
nero para la especie, abre expectativas para el uso potencial de callos de $U$. molinae en otras aplicaciones tales como, la producción de protoplastos, híbridos somáticos, embriones somáticos y su utilización en la poliploidización.

\section{CONCLUSIONES}

Los cotiledones e hipocótilos son los explantes más apropiados para el desarrollo de callos en $U$. molinae, estos incluso pueden prescindir de la adición de hormonas exógenas en la fase de inducción. El tipo de callo depende tanto del tipo de explante y del tratamiento hormonal. La ausencia de reguladores de crecimiento en los medios de inducción estimula la presencia de callos verdes, mientras que los tratados con reguladores de crecimiento son en su mayoría friables y fenólicos. Los tratamientos ensayados en $U$. molinae potencian preferentemente el proceso de rizogénesis comparado con el de caulogénesis.

\section{REFERENCIAS}

Al Abdallat A, J Sawwan, B Al Zoubi. 2011. Agrobacterium tumefaciens-mediated transformation of callus cells of Crataegus aronia. Plant Cell, Tissue and Organ Culture 104: 31-39. DOI: 10.1007/s11240-010-9798-1.

Ainsley P, G Collins, M Sedgley. 2000. Adventitious shoot regeneration from leaf explants of almond (Prunus dulcis Mill.). In vitro Cellular and Developmental Biology-Plant 36: 470-474.

Bandyopadhyay S, C Karen, R Gillian, D John. 1999. Efficient plant regeneration from seedling explants of two commercially important temperate eucalypt species Eucaliptus nitens and E. globulus. Plant Science 140: 189-198.

Correia S, J Canhoto. 2010. Characterization of somatic embryo attached structures in Feijoa sellowiana Berg. (Myrtaceae). Protoplasma 242: 95-107. DOI: 10.1007/s00709-0100130-z.

Delporte C, N Backhouse, V Inostroza, M Aguirre, N Peredo, X Silva. 2007. Analgesic activity of Ugni molinae (murtilla) in mice models of acute pain. Journal of Ethnopharmacology 112(1): 162-165.

Feeney M, B Bhagwat, J Mitchell, W Lane. 2007. Shoot regeneration from organogenic callus of sweet cherry (Prunus avium L.). Plant Cell, Tissue and Organ Culture 90: 201-214.

Glocke P, G Collins, M Sedgley. 2006. Effects of auxins on organogenesis and somatic embryogenesis from juvenile explants of Eucalyptus erythronema, E. stricklandii, and two inter-specific hybrids. Journal of Horticultural Science and Biotechnology 81(6): 1009-1014.

Gómez C, M Uribe, D Rios, M Sanchez. 2006. Inducción de callo embriogénico en Eucaliptus globulus Labill. Interciencia 31(10): 734-738.

Hajari E, M Watt, D Mycock, B McAlister. 2006. Plant regeneration from induced callus of improved Eucalyptus clones. South African Journal of Botany 72: 195-201.
Hoffmann A. 2005. Flora silvestre de Chile. Zona Araucana. Quinta edición. Fundación Claudio Gay. Santiago, Chile. 258 p.

Larson C, C Gómez, M Sánchez, D Ríos. 2006. Inducción de caulogénesis indirecta en Eucalyptus globulus. Bosque 27(3): 250-257.

Meiners, J, M Schwab, I Szankowski. 2007. Efficient in vitro regeneration systems for Vaccinium species. Plant Cell, Tissue and Organ Culture 89:169-176.

Murashige T, F Skoog. 1962. A revised medium for rapid growth and bio assays with tobacco tissue cultures. Physiologia Plantarum 15: 473-497.

Pinto G, C Santos, L Neves, C Aráujo. 2002. Somatic embryogenesis and plant regeneration in Eucaliptus globulus Labill. Plant Cell Reports 21: 208-213. DOI: 10.1007/s00299002-0505-5.

Prakash M, K Gurumurthi. 2010. Effects of type of explant and age, plant growth regulators and medium strength on somatic embryogenesis and plant regeneration in Eucalyptus camaldulensis. Plant Cell, Tissue and Organ Culture 100: 13-20. DOI: 10.1007/s11240-009-9611-1.

Rashmi R, M Trivedi. 2014. Effect of Various Growth Hormone Concentration and Combination on Callus Induction, Nature of Callus and Callogenic Response of Nerium odorum. Applied Biochemistry and Biotechnogy. DOI 10.1007/ s12010-013-0693-1.

Rodríguez M. 2000. Análisis de la diversidad fenotípica de murta (Ugni molinae Turcz.) a través de métodos multivariados. Tesis Magister en Ciencias. Valdivia, Chile. Facultad de Ciencias Agrarias, Universidad Austral de Chile. 177 p.

Rodríguez M. 2011. La propagation d'écotypes sélectionnés de murtilla (Ugni molinae Turcz.), une baie endémique du Chili: étude de la germination et stratégies de multiplication in vitro. Tesis doctoral. Paris, Francia. Institut des Sciences et Industries du Vivant et de l'Environnement, AgroParisTech. Ecole Doctorale ABIES. 232 p.

Sala F, M Labra. 2003. Somaclonal variation. In Thomas B, DJ Murphy, B Murray eds. Encyclopedia Appl. Plant Sci. Oxford, UK. Academic Press Elsevier. p. 1417-1422.

Shiram V, V Kumar, M Shitole. 2008. Indirect organogénesis and plant regeneration in Helicteres isora L., an important medicinal plant. In vitro Cellular and Developmental BiologyPlant 44:186 DOI: 10.1007/s11627-008-9108-3.

Smith R. 2012. Plant tissue culture: Techniques and experiments. Londres, UK. Academic Press Elsevier. 208 p.

Stefanello S, L Dal Vesco, J Ducroquet, R Nodari, M Guerra. 2005. Somatic embryogenesis from floral tissues of feijoa (Feijoa sellowiana Berg). Scientia Horticulturae 105: 117-126.

Tang W, R Newton. 2005. Plant regeneration from callus cultures derived from mature zygotic embryos in white pine ( $\mathrm{Pi}$ nus strobes L.). Plant Cell Reports 24: 1-9. DOI: 10.1007/ s00299-005-0914-3.

Trabelsi E, S Naija, N Elloumi, Z Belfeleh, M Msellem, R Ghezel, S Bouzid. 2010. Somatic embryogenesis in cell suspension cultures of olive Olea europaea (L.) 'Chetoui'. Acta Physiologiae Plantarum 33(2): 319-324. DOI: 10.1007/ s11738-010-0550-6. 